Bull. Mater. Sci., Vol. 21, No. 1, February 1998, pp. 71-75. (C) Printed in India.

\title{
A possible crystallographic explanation for the five-fold diffraction symmetry in icosahedral phases
}

\author{
T R ANANTHARAMAN \\ Metals and Alloys Group, National Physical Laboratory, Dr K S Krishnan Road, New Delhi 110012, India \\ MS received 16 December 1997

\begin{abstract}
X-ray and electron diffraction data from the $\mathrm{Al}-\mathrm{Cu}-\mathrm{Fe}$ icosahedral phase are compared and analysed on the basis of the microcrystalline and multi-domain model developed by the author. It is shown that a crystallographic explanation is now possible for both the enigmatic five-fold symmetry and non-periodicity of reflections observed in electron diffraction patterns of icosahedral phases.
\end{abstract}

Keywords. Crystallography; diffraction symmetry; icosahedral phases.

\section{Introduction}

The discovery of quasicrystalline alloy phases (Schechtman et al 1984) displaying crystallographically disallowed five-fold diffraction symmetry has generated a great deal of excitement, as also some confusion and controversy, in scientific circles (Kelton 1993). One of the fundamental issues raised by intensive researches on icosahedral and decagonal quasicrystals relates to the limits of our ability to distinguish through experiment between true quasicrystals and multi-twinned or multi-domain crystals with large unit cells (Goldman and Kelton 1993). A further important recent development in this regard has been the discovery of many so-called crystalline or rational approximants (see, for example, Liu 1993), which seem to have atomic arrangements in their rather large unit cells closely resembling the local atomic structure in quasicrystals.

Starting with Field and Fraser (1985), many investigators (Carr 1986; Pauling 1985, 1987, 1988, 1990; Vecchio and Williams 1988; Anantharaman 1989, 1990, 1993, 1994a) have sought a conventional crystallographic explanation for the quasicrystal phenomenon in terms of very large unit cells or multi-twinned crystals. Interest in multi-twinned or multi-domain crystalline aggregates has been revived in recent years by reports in their favour based on high-resolution single crystal synchrotron $\mathrm{X}$-ray studies of two thermodynamically stable and "perfect' quasicrystals, e.g. Al-Cu-Fe icosahedral phase (Motsch et al 1992) and $\mathrm{Al}-\mathrm{Cu}-\mathrm{Co}(-\mathrm{Si})$ decagonal phase (Fettweis et al 1993, 1994). As pointed out by Steurer (1996) in his most recent review, practically all quasicrystals transform to crystalline phases at lower temperatures or under high pressure, running through intermediate phases with rather complicated and/or nanodomain structures.
In this paper, $\mathrm{X}$-ray and electron diffraction data from $\mathrm{Al}-\mathrm{Cu}-\mathrm{Fe}$ icosahedral phase is presented and analysed on the basis of the microcrystalline and multi-domain model developed by the author for both icosahedral and decagonal phases (Anantharaman 1993). A crystallographic explanation is thereby sought for the unusual five-fold symmetry and nonperiodicity of reflections observed in electron diffraction patterns of all icosahedral phases.

\section{Experimental}

Alloys with the nominal composition $\mathrm{Al}_{65} \mathrm{Cu}_{20} \mathrm{Fe}_{15}$ were prepared by arc melting in purified argon atmosphere and then rapidly solidified by planar flow casting. The resulting ribbons (20-30 $\mu \mathrm{m}$ thick) were examined before and after annealing at $1073 \mathrm{~K}$ for $8 \mathrm{~h}$ in a Siemens Rotating Anode X-ray Diffractometer, using $\mathrm{CuK}_{\alpha}$ or $\mathrm{CoK}_{\alpha}$ monochromatic radiation. Transmission electron microscopic studies were also conducted in a JEOL JEM-200CX $200 \mathrm{kV}$ Electron Microscope after thinning the ribbons by chemical means or by ion beam in a BAL-TEC RES 010 Rapid Etching System. As has been reported earlier (Ishimasa et al 1988; Liu 1993), the rapidly solidified ribbons were characterized by a homogenous icosahedral phase, while the annealed samples revealed also traces of the monoclinic $\mathrm{Al}_{13} \mathrm{Fe}_{4}$ phase. The two thinning techniques employed to produce specimens transparent to the electron beam did not make any difference to the electron diffraction data, as presented and analysed in this paper.

Table 1 presents results of an analysis of the first 32 Debye-Scherrer reflections with intensities of at least $1 \%$ of the strongest one from $i-\mathrm{Al}-\mathrm{Cu}-\mathrm{Fe}$ on the basis of the model proposed by the author (Anantharaman $1989,1993,1994 b)$ for the multi-domain crystallization 
of icosahedral and decagonal phases through nucleation from icosahedral atomic clusters in the concerned alloy melts. The orthorhombic unit cell built up of 96 orthorhombic basic cells with $a=6 a^{\prime}=1.4868 \mathrm{~nm}$, $b=4 b^{\prime}=1.6840 \mathrm{~nm}$ and $c=4 c^{\prime}=1.6024 \mathrm{~nm}$ and belonging to the space group $P_{m m m}$ (No. 47), as assigned here to $i-\mathrm{Al}-\mathrm{Cu}-\mathrm{Fe}$, is quite similar to the ordered orthorhombic unit cells proposed earlier for $i-\mathrm{Al}-\mathrm{Mn}, i-\mathrm{Al}-\mathrm{Mn}-\mathrm{Si}$, $i-\mathrm{Al}-\mathrm{Cu}-\mathrm{Mg}, \quad i-\mathrm{Al}-\mathrm{Cu}-\mathrm{Li}$ and $i-\mathrm{Al}-\mathrm{Cu}-\mathrm{Ru}$ phases. Depending on the actual composition, method of preparation and subsequent heat treatment, the parameters of the $i-\mathrm{Al}-\mathrm{Cu}-\mathrm{Fe}$ refined basic cell have been found to vary over a small range viz. $a^{\prime}=0.248-0.252 \mathrm{~nm}$; $b^{\prime}=0.421-0.429 \mathrm{~nm}$ and $c^{\prime}=0.400-0.408 \mathrm{~nm}$. The agreement between calculated and observed interplanar distances $\left(d_{h k l}\right)$ is extremely satisfactory in this case, the

Table 1. Comparison of calculated and observed interplanar distances ( $d_{\mathrm{cal}}$ and $d_{\mathrm{obs}}$ in nanometers) and observed relative intensities $\left(I_{\mathrm{obs}}\right)$ for Debye-Scherrer reflections from $\mathrm{Al}-\mathrm{Cu}-\mathrm{Fe}$ icosahedral phase.

\begin{tabular}{|c|c|c|c|c|}
\hline No. & $h k l$ & $d_{\text {cal }}$ & $d_{\text {obs }}$ & $I_{\mathrm{obs}}$ \\
\hline 1 & 020 & 0.842 & 0.833 & 2 \\
\hline 2 & 220 & $0.557 /$ & & \\
\hline 3 & 202 & 0.545 & 0.551 & 3 \\
\hline 4 & 040 & $0.421 /$ & & \\
\hline 5 & 004 & 0.401 & 0.415 & 3 \\
\hline 6 & 042 & 0.373 & 0.374 & 13 \\
\hline 7 & 420 & $0 \cdot 340 /$ & & \\
\hline 8 & 402 & 0.337 & 0.339 & 15 \\
\hline 9 & 224 & 0.325 & 0.324 & 12 \\
\hline 10 & 440 & 0.279 & 0.280 & 3 \\
\hline 11 & 600 & 0.248 & 0.245 & 7 \\
\hline 12 & 602 & 0.237 & 0.238 & 3 \\
\hline 13 & 444 & 0.229 & 0.229 & 2 \\
\hline 14 & 604 & $0.211 /$ & & \\
\hline 15 & 080 & 0.211 & 0.211 & 94 \\
\hline 16 & 642 & 0.206 & 0.206 & 2 \\
\hline 17 & 624 & 0.204 & 0.204 & 2 \\
\hline 18 & 008 & 0.200 & 0.200 & 100 \\
\hline 19 & 644 & 0.189 & 0.188 & 1 \\
\hline 20 & 428 & 0.173 & 0.173 & 3 \\
\hline 21 & 448 & 0.163 & 0.162 & 2 \\
\hline 22 & 088 & 0.145 & 0.145 & 13 \\
\hline 23 & $0 \cdot 10 \cdot 6$ & 0.143 & 0.142 & 4 \\
\hline 24 & $10 \cdot 44$ & 0.132 & 0.133 & 1 \\
\hline 25 & $22 \cdot 12$ & $0.130 /$ & & \\
\hline 26 & 848 & 0.130 & 0.130 & 1 \\
\hline 27 & 12.00 & 0.124 & 0.124 & 36 \\
\hline 28 & 12.42 & 0.118 & 0.117 & 2 \\
\hline 29 & $12 \cdot 80$ & 0.107 & $0 \cdot 107$ & 20 \\
\hline 30 & 12.08 & $0 \cdot 105 /$ & & \\
\hline 31 & $0.16 \cdot 0$ & 0.105 & 0.105 & 15 \\
\hline 32 & $00 \cdot 16$ & 0.100 & $0-100$ & 1 \\
\hline
\end{tabular}

Unit cell: Orthorhombic Space group: $P_{m m m}$ (No. 47) $I_{\text {obs: }}$ Rounded to integers (Weak reflections with $I_{\text {obs }}$ less than 1.0 are not included). indices of all recorded reflections being significantly common to both face-centred cubic (fcc) and body-centred cubic (bcc) structures (table 1).

Table 2 contains an analysis of the selected area electron diffraction pattern of $i-\mathrm{Al}-\mathrm{Cu}-\mathrm{Fe}$, displaying the well-publicized and much-discussed five-fold symmetry first observed in $i-\mathrm{Al}-\mathrm{Mn}$ (Schechtman et al 1984) and subsequently in many other icosahedral phases. Among over 200 reflections or spots recorded in this pattern, it could be noted that 130 reflections are equally distributed in 10 rows, each row starting from the origin and displaying an angle of $36^{\circ}$ to its neighbours on either side. Their interplanar distances $\left(d_{h k l}\right)$ were calculated from several rows of reflections and from many diffraction patterns of $i-\mathrm{Al}-\mathrm{Cu}-\mathrm{Fe}$ with differing camera lengths. The reliable and reproducible averages of the observed $d_{h k l}$ values for a row of reflections are recorded in column 2 of table 2 , their relative intensities $\left(I_{R}\right)$ being shown in column 3 . The nonperiodicity of the diffraction spots in such patterns has generally been explained on the basis of the so-called Fibonacci sequence, viz. $2,3,5,8,13,21$, etc. Columns 4 and 5 of table 2 attempt an analysis of the concerned $d_{h k l}$ values on this basis and show that there is considerable deviation between the estimated and observed values in case of the low-angle reflections.

The X-ray evidence in table 2 studied along with the proposal in the author's multi-domain model for the emergence of five-fold diffraction symmetry in icosahedral phases (see Anantharaman 1994b), as illustrated in figure 1 , brings out some very significant and interesting features (see column 6 of table 2) of the five-fold electron diffraction patterns of $i-\mathrm{Al}-\mathrm{Cu}-\mathrm{Fe}$. Based on the [110] zone for one orientation, the very strong 008 reflection along with its rather weak second order companion, i.e. $00 \cdot 16$ reflection, appears as expected in every one of the ten rows of reflections, but the only other reflection that can be identified from $X$-ray patterns is 224, along with its second order, i.e. 448. The latter pair actually comes from a crystal (or domain) with a different orientation, inclined $72^{\circ}$ to the original crystal, and appears on this line or row only because the angle between 001 and 112 crystallographic planes in this orthorhombic phase works out to almost exactly $36^{\circ}$. No other reflection on this row can be identified in the concerned Debye-Scherrer patterns. Of course the observed $d_{h k l}$ values of two electron reflections, viz. $0.144 \mathrm{~nm}$ and $0.123 \mathrm{~nm}$, have their counterparts in the X-ray pattern, viz. $0.145 \mathrm{~nm}$ for 088 and $0.124 \mathrm{~nm}$ for 12.00 , but these two reflections cannot possibly appear in the [110] zone under consideration.

As regards the 9 electron reflections in each row, that are not accounted for in the Debye-Scherrer patterns, the last column of table 2 brings out the real reason for their appearance, viz. they are all caused by dynamic 
Table 2. Analysis of a representative set from the ten identical rows of reflections in the electron diffraction pattern of AlCuFe icosahedral phase.

\begin{tabular}{|c|c|c|c|c|c|c|}
\hline No. & $\begin{array}{c}d_{h k l} \\
\text { observed }\end{array}$ & $I_{\mathrm{R}}$ & $h k l_{\mathrm{F}}$ & $\begin{array}{c}d_{h l l} \\
\text { calculated }\end{array}$ & $X$-ray evidence & Double diffraction possibility \\
\hline 1 & 0.850 & $w$ & 002 & 0.801 & not observed & $0.527+0.324=0.851$ \\
\hline 2 & 0.527 & $\mathrm{~m}$ & 003 & 0.534 & not observed & $0.324+0.200=0.524$ \\
\hline 3 & 0.324 & $\mathrm{~s}$ & 005 & 0.320 & observed, $d_{224}=0.324$ & not called for \\
\hline 4 & 0.261 & $\mathrm{vw}$ & 006 & 0.267 & not observed & $0.162+0 \cdot 100=0.262$ \\
\hline 5 & 0.234 & $\mathrm{vw}$ & 007 & 0.229 & not observed & $0.145+0.090=0.235$ \\
\hline 6 & 0.200 & vs & 008 & 0.200 & observed, $d_{048}=0.200$ & not called for \\
\hline 7 & $0 \cdot 162$ & $\mathrm{vw}$ & $00 \cdot 10$ & $0 \cdot 160$ & observed, $d_{148}=0.162$ & not called for \\
\hline 8 & 0.144 & vw & $00 \cdot 11$ & 0.146 & not observed & $0.234-0.090=0.144$ \\
\hline 9 & 0.123 & $\mathbf{s}$ & $00 \cdot 13$ & 0.123 & not observed & $0.324-0.200=0.124$ \\
\hline 10 & $0 \cdot 100$ & $\mathrm{~m}$ & $00 \cdot 16$ & 0.100 & observed, $d_{00.16}=0.100$ & not called for \\
\hline 11 & 0.090 & $\mathrm{~m}$ & $00 \cdot 18$ & 0.089 & no data & $0.234-0.145=0.089$ \\
\hline 12 & 0.076 & $\mathrm{~s}$ & $00 \cdot 21$ & 0.076 & no data & $0.200-0.123=0.077$ \\
\hline 13 & 0.062 & $\mathrm{~s}$ & $00 \cdot 26$ & 0.062 & no data & $0.162-0.100=0.062$ \\
\hline
\end{tabular}

$\left(I_{\mathrm{R}}=\right.$ Relative observed intensity; $\mathrm{vW}=$ very weak; $\mathrm{w}=$ weak; $\mathrm{m}=$ medium; $\mathrm{s}=$ strong; $\mathrm{vs}=$ very strong, $h l_{\mathrm{F}}=$ indices based on the Fibonacci sequence: $d_{l k l l}=$ values in nanometers).

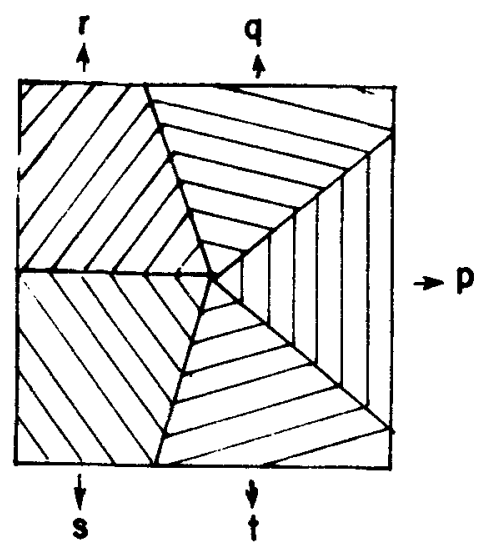

(a)

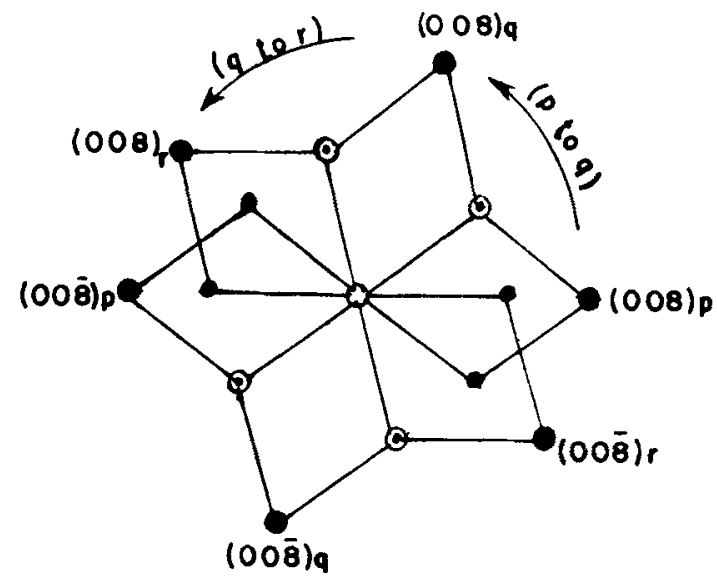

(c)

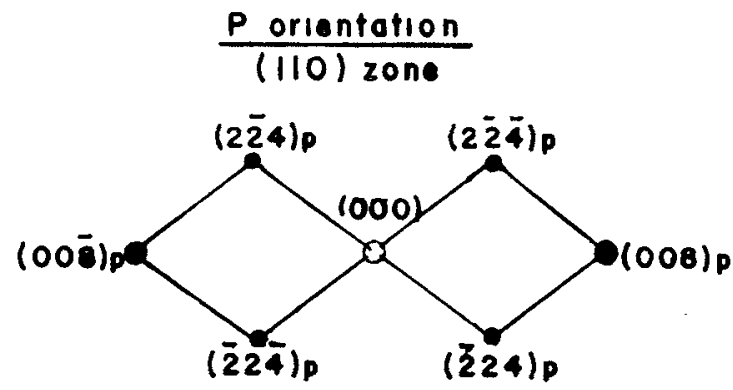

(b.)

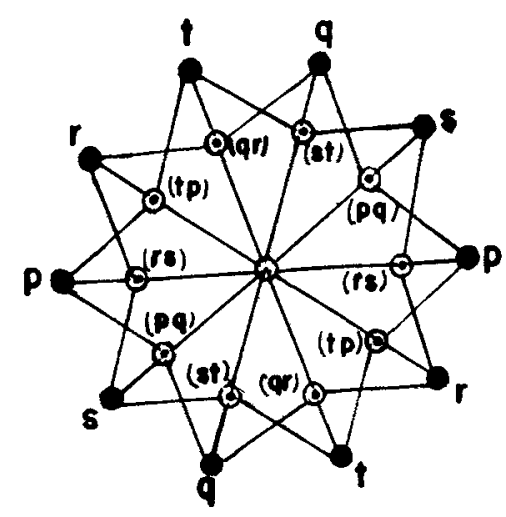

(d)

Figure 1. Emergence of the five-fold electron diffraction pattern of an icosahedral phase prior to double diffraction. (a) Five orientations of the same crystal $\left(p, q, r, s\right.$ and $t$ ) with $72^{\circ}$ angular relationships between them, (b) single crystal diffraction pattern: [110] zone, " $p$ " orientation, (c) impact of two other orientations ( $q$ and $r$ ) on (b), and (d) diffraction pattern generated by all five $(p, q, r, s$ and $t)$ orientations before double diffraction. 
double diffraction, a phenomenon known for long to cause extra spots in electron diffraction patterns. In fact, computer simulation has earlier been used to confirm the emergence of such extra reflections due to double diffraction in icosahedral phases (Field and Fraser 1985; Anantharaman 1989). It is relevant to add here that in this case actual experimental demonstration, through dark field characterization and tilting, of the occurrence of extra reflections due to double diffraction is extremely difficult, if not impossible, because of the complex multi-domain structure assigned to such phases.

\section{Discussion of results}

In the present work, perhaps for the first time, a careful and detailed analysis has been undertaken of both X-ray and electron diffraction patterns from the same icosahedral phase on the basis of a crystallographic model. The observed five-fold diffraction symmetry is shown to be caused by one very strong reflection (along with its second order) from a crystal of the icosahedral phase with a particular orientation and another not so strong reflection (along with its second order) from the same type of crystal, but with a $72^{\circ}$ orientation relationship with the former. These four electron spots in each of the ten rows of spots radiating or spreading out from the origin at $36^{\circ}$ intervals are shown to generate another nine spots by dynamic double diffraction. Thus 130 electron reflections get recorded in ten rows of the diffraction pattern through just two reflections, one each from two orientations, $72^{\circ}$ to each other! In fact, many other reflections in the diffraction patterns can also be explained as only due to double diffraction from these four reflections.

The nonperiodicity and Fibonacci sequence, associated with the electron reflections in such patterns for nearly a decade, can thus be seen to arise out of some extraordinarily unusual circumstances related to the icosahedral phases, viz. the geometry of the unit cell-leading to an angle of $36^{\circ}$, i.e. half of $72^{\circ}$, between the 001 and 112 planes, the emergence of five $72^{\circ}$ orientations of the crystal due to random changes in direction during its growth and the fortuitous closeness between the 224 and 005 interplanar distances $(0.324 \mathrm{~nm}$ and $0.320 \mathrm{~nm}$, respectively). Further, such a five-fold pattern is not generated by the 800 and 080 reflections since the concerned crucial angular relationships viz. between 800 and 422 in the [011] zone and between 080 and 242 in the [101] zone, work out to $33^{\circ}$ and $38^{\circ}$, respectively, and not $36^{\circ}$. Incidentally, the 800 reflection does not appear in the X-ray pattern, but 12.00 does (see table 1 ). It is relevant to report here that the extraordinary role of unit cell geometry in causing five-fold electron diffraction has recently been highlighted in case of a well-known crystalline phase viz. orthorhombic $\mathrm{Al}_{13} \mathrm{Fe}_{4}$ (Ellner 1995).
It is appropriate to record here that the lattice parameters of $i-\mathrm{Al}-\mathrm{Cu}-\mathrm{Fe}$ may well be higher than the values used in the present analysis, depending on the appearance and identification of further weak Debye-Scherrer reflections at very low Bragg angles. In fact, a much larger rhombohedral unit cell has already been proposed (Motsch et al 1992) for $i-\mathrm{Al}-\mathrm{Cu}-\mathrm{Fe}$ with $\gamma=3.208 \mathrm{~nm}$ and $\alpha=36^{\circ}$ on the basis of high resolution synchrotron $\mathrm{X}$-ray studies of this phase. This unit cell can be converted to the orthorhombic system with $a=1.983 \mathrm{~nm}$; $b=3.434 \mathrm{~nm}$ and $c=8.978 \mathrm{~nm}$. On the basis of the author's model, these parameters work out to $8 a^{\prime}, 8 b^{\prime}$ and $22 c^{\prime}$, respectively, allowing for the slight differences in chemical composition of the two alloys concerned. So long as the proposed unit cells constitute superstructures of the small basic orthorhombic cell identified in the author's model (Anantharaman 1994b), as shown in this case, the present analysis can be applied convincingly and with the same conclusions to all icosahedral phases, albeit with different and numerically higher indices for the crucial 008 and 224 reflections.

\section{Acknowledgements}

The experimental work described above was carried out during a six-week visit to the Institute for Solid State and Materials Research, Dresden, Germany. Author thanks Mr R Rennekamp of this Institute's Electron Microscopy Division, for his valuable assistance in thinning and mounting specimens, as also examining them in the electron microscope. He also thanks Prof. H Warlimount, Scientific Director, Dr H D Bauer, Head, Electron Microscopy Division, and Dr N Mattern, Head, X-ray Crystallography Division, of this Institute for their encouragement and support. He is indebted to the Director General, Council of Scientific and Industrial Research, New Delhi for nominating him on an Indo-German Exchange Programme for this Research Visit to Dresden.

\section{References}

Anantharaman T R 1989 Curr. Sci. 581057

Anantharaman T R 1990 Quasicrystals and incommensurate structures in condensed matter (eds) M J Yacaman, D Romeu, V Castano and A Gomez (Singapore: World Scientific) p. 199

Anantharaman T R 1993 Scr. Met. Mater. 281555

Anantharaman T R 1994a Experimental methods of phase diagram determination (eds) J E Morral, $\mathrm{R} S$ Schiffman and S M Merchant (USA: TMS) p. 173

Anantharaman T R 1994b Bull. Mater. Sci. 17717

Carr M J 1986 J. Appl. Phys. 591063

Ellner M 1995 Acta Cryst. B51 31

Fettweis M, Launois P, Denoyer F, Reich R, Godard J M and Lambert M 1993 J. Non-Cryst. Solids 153/154 24

Fettweis M, Launois P. Denoyer F, Reich R and Lambert M 1994 Phys. Rev. B49 15573 
Field R D and Fraser H L 1985 Mater. Sci. Eng. 68 L17 Goldman A I and Kelton K J 1993 Rev. Mod. Phys. 65213 Ishimasa T, Fukano $\mathrm{Y}$ and Tsuchimori M 1988 Philos. Mag. Lett. 58157

Kelton K F 1993 Int. Mater. Rev. 38105

Liu W 1993 Fortschritt-Berichte VDI Reihe 5, No. 300

Motsch T, Denoyer F, Launois P and Lambert M 1992 J. Phys. I France 2861

Pauling L 1985 Nature 317512
Pauling L 1987 Phys. Rev. Lett. 58365

Pauling L 1988 Proc. Natl. Acad. Sci. 858276

Pauling L 1990 Proc. Natl. Acad. Sci. 877849

Schechtman D, Blech I, Gratias D and Cahn J W 1984 Phys. Rev. Lett. 531951

Steurer W 1996 Physical metallurgy (eds) R W Cahn and P Haasen (Elsevier Science BV) 4th ed., p. 372

Vecchio K S and Williams D B 1988 Metall. Trans. A19 2875 